\title{
Psicoterapia de grupo em hospital-dia psiquiátrico ${ }^{1}$
}

\author{
Ana Celina Pires de Campos Guimarães ${ }^{2}$ \\ Universidade do Sagrado Coração, Bauru-SP, Brasil \\ José Onildo Betioli Contel \\ Universidade de São Paulo, Ribeirão Preto-SP, Brasil
}

\begin{abstract}
Resumo: Este estudo objetivou estudar a psicoterapia de grupo em um hospital-dia psiquiátrico, caracterizando os pacientes dos grupos, os temas discutidos, a frequência das verbalizações e o manejo terapêutico das sessões. O método foi quantiqualitativo, categorial temático. Os pacientes eram heterogêneos e os grupos abertos, com duração de uma hora. Emergiram dos grupos seis categorias temáticas. Os pacientes verbalizaram $56 \%$ do total das 2.459 falas. No manejo técnico das sessões predominou o apoio, a ênfase no aqui-e-agora e a estrutura na condução dos grupos. Concluiu-se que, nas sessões analisadas, houve espaço para a fala dos pacientes, sendo estas manejadas terapeuticamente.
\end{abstract}

Palavras-chave: distúrbios mentais, serviços de saúde mental, psicoterapia de grupo.

\section{Group psychotherapy at a psychiatric day-hospital}

\begin{abstract}
This study evaluated psychotherapy group at a psychiatric day-hospital, characterizing the groups' structure, content, frequency of verbalization and therapeutic management of meetings. Quantitative and qualitative methods with a categorical thematic approach were used. The patients were heterogeneous and groups were open with one-hour meetings. Six categories emerged from the thematic groups. The participants verbalized $56 \%$ of the 2,459 verbal accounts. During technical management of meetings predominated: support, emphasis on the here-and-now, and structure in guiding group behavior. The conclusion is that there were opportunities for patients to express themselves and these manifestations were therapeutically managed.
\end{abstract}

Keywords: mental disorders, mental health services, group psychotherapy.

\section{Psicoterapia de grupo en hospital-día psiquiátrico}

Resumen: El objetivo de este trabajo fue estudiar la psicoterapia de grupo en un hospital-día psiquiátrico, investigando las características de los pacientes en los grupos, los temas discutidos, la frecuencia de las verbalizaciones y el manejo de las sesiones terapéuticas. La metodología utilizada ha sido cuantitativa y cualitativa. Los pacientes eran heterogéneos y los grupos abiertos, con sesiones de una hora de duración. Seis categorías temáticas emergieron de los grupos. Los pacientes verbalizaron 56\% del total de los 2.459 registros orales. En el manejo técnico de las sesiones predominó el apoyo, el énfasis en lo aquí-y-ahora y la estructura en la conducción de los grupos. Se concluye que, en las sesiones analizadas, hubo espacio para las manifestaciones orales de los pacientes, que han sido conducidas terapéuticamente.

Palabras clave: transtornos mentales, servicios de salud mental, psicoterapia de grupo.

Os grupos oferecem espaço para a comunicação e interação possibilitando aos seus integrantes representar, neste contexto, seu microcosmo social (Vinogradov \& Yalom, 1992). A psicoterapia de grupo é considerada uma importante modalidade de tratamento em saúde mental, proporcionando espaço para a fala e para a escuta (Contel e cols., 1993; Guimarães, 2001). A primeira experiência com grupo é atribuída ao americano Joseph H. Pratt em 1905 com pacientes que sofriam de tuberculose, ele observou que os pacientes ao compartilharem problemas demonstraram maior confiança e esperança, gerando melhora. Essa prática estendeu-se aos doentes mentais e depois a outras patologias.

1 Este artigo é derivado da dissertação de mestrado da primeira autora intitulada "Grupoterapia em hospital-dia: Análise temática de quinze sessões", apresentada à Faculdade de Medicina de Ribeirão Preto da Universidade de São Paulo, como parte das exigências para a obtenção do título de Mestre em Saúde Mental. A autora agradece especialmente a seu orientador Prof. Dr. José Onildo Betioli Contel.

2 Endereço para correspondência:

Ana Celina Pires de Campos Guimarães. Rua Engenheiro Alpheu José Ribas Sampaio, 230, apto. 161. CEP 17.012-631. Bauru-SP, Brasil. E-mail: acpc.guima@bol.com.br
Bechelli e Santos (2004) citam como precursores da psicoterapia de grupo, na década de 1920 e 1930, Pratt, Marsh, Lazell e Burrow na América e na Europa Moreno, Adler, Metzl, Bion entre outros. Discorrem que nos anos 1950 e 1960 houve grande expansão teórica e que a década de 1970 marcou a consolidação da técnica grupal. Os anos 1980 e 1990 retrataram seu amadurecimento, quanto aos aspectos técnicos e ao atendimento a diferentes populações. Nas últimas décadas as intervenções grupais têm sido cada vez mais utilizadas em diferentes contextos (Zimerman \& Osório, 1997).

Os grupos podem ser conduzidos em settings ambulatoriais ou de internação. $\mathrm{O}$ grupo pode ser aberto, no qual ocorre rotatividade de pacientes; ou fechado onde os pacientes permanecem os mesmos durante um período limitado de tempo. Os grupos podem ser homogêneos ou heterogêneos quanto ao diagnóstico e características dos pacientes. Contudo seja qual for a orientação teórica, a modalidade de intervenção grupal apresenta três características indispensáveis: o setting, os objetivos e a estrutura do tempo. O terapeuta deve coordenar o andamento do grupo, oferecendo suporte, e garantindo um clima de compreensão, respeito e empatia (Contel, 1997; Guanaes \& Japur, 2001b; Guimarães, 2001; Guimarães \& Contel, 2006). 
Nas psicoterapias de grupo, independentemente da modalidade, o potencial terapêutico e a força para a mudança decorrem da interação entre os membros do grupo (Guanaes \& Japur, 2001a; Guimarães, 2001; Bechelli \& Santos, 2001, 2002). Deste modo o fator terapêutico é gerado pelo grupo e contribui para a melhoria da condição de cada um. Vinogradov e Yalom (1992) relatam onze fatores terapêuticos presentes, em maior ou menor grau, nas psicoterapias de grupo: instilação de esperança; universalidade; oferecimento de informações, altruísmo, desenvolvimento de técnicas de socialização, comportamento imitativo, catarse, reedição corretiva do grupo familiar primário, fatores existenciais, coesão do grupo, aprendizagem interpessoal. Discutem ainda, que no manejo de grupos com pacientes psicóticos em internação integral ou parcial devem ocorrer ajustes técnicos tais como: considerar o tempo de um grupo como sendo de uma sessão em função da rotatividade dos pacientes devido a admissões e altas; minimizar o conflito e salientar o apoio; foco no aquie-agora, especialmente nas relações interpessoais; propocionar estrutura no setting por meio da repetição consistente de eventos. Os autores ressaltam ainda que trabalhar dentro de uma instituição requer o estabelecimento de limites semipermeáveis entre o ambiente institucional e o do grupo de modo a garantir o funcionamento e a coesão do grupo.

No Brasil, com as propostas da reforma psiquiátrica ocorreu a reorganização do modelo assistencial em saúde mental e a psicoterapia de grupo passou a ser muito utilizada em diferentes ambientes institucionais por responder à intensa demanda de pacientes, oferecer vantagens de custo em comparação ao atendimento individual e sobretudo por diminuir o isolamento social do doente mental (Bezerra Junior, 1992; Guimarães, 2001). Contudo, conforme discutem Scherer e Scherer (2001), é necessário atenção ao modelo de serviços oferecidos aos doentes mentais crônicos, especialmente no cuidado em manter uma mesma equipe básica. De Tílio (2007) também discute que apesar da reforma psiquiátrica e da luta antimanicomial no Brasil terem apresentado avanços no entendimento e tratamento ao doente mental, muito ainda tem que ser conquistado, especialmente no status sóciojurídico dessas pessoas.

Contel (1991) relata que em 1974 ao retomarem a experiência no Hospital-Dia (HD) da Faculdade de Medicina de Ribeirão Preto (FMRP) da Universidade de São Paulo (USP), três princípios complementares foram tomados como base: (a) aplicação intensiva do trabalho terapêutico com ênfase na psicoterapia de grupo, sob a forma de grupos operativos; (b) utilização compreensiva do trabalho sistemático em equipe multidisciplinar, objetivando o desenvolvimento da interdisciplinaridade; (c) entendimento da instituição como um sistema que dá respostas próprias e ao mesmo tempo é influenciado e também influencia os grupos terapêuticos e a equipe multidisciplinar.

O exercício da complementaridade entre esses três princípios tornou-se um método de trabalho. Segundo Contel (1991), sua aplicação no desenvolvimento técnico e humano dos profissionais e alunos e no aprimoramento do tratamento dos pacientes tem sido característica deste HD. Contel e cols. (1993) ao relatarem a psicoterapia de grupo com pacientes psicóticos em internação parcial no HD verificaram a melhora dos pacientes no que diz respeito à socialização, ao grau de percepção quanto ao próprio comportamento à diminuição de recidivas, destacando que a coesão grupal e o aprendizado interpessoal são fatores terapêuticos importantes nos grupos com pacientes psiquiátricos. Tapia, Contel e Campos (1997) descrevem que a experiência terapêutica grupal proporcionou o sentido de reconstrução existencial do mundo do paciente.

A autora deste trabalho realizou observação em settings grupais de um hospital-dia universitário, durante um ano, duas vezes por semana. Frente à riqueza dos dados emergentes nos grupos sentiu-se extremamente mobilizada em efetuar um estudo que caracterizasse esses grupos e seus pacientes. Este artigo apresenta alguns dados obtidos através desse estudo (Guimarães, 1998, 2001).

\section{Método}

Utilizou-se o método quanti-qualitativo do tipo categorial temático, proposto pela análise de conteúdo de Bardin (1979, p. 42), que pode ser definido como:

Um conjunto de técnicas de análise das comunicações, visando obter por procedimentos sistemáticos e objetivos de descrição do conteúdo das mensagens, indicadores (quantitativos ou não) que permitam a inferência de conhecimentos destas mensagens.

\section{Participantes}

Participaram deste estudo um total de 26 pacientes, que passaram pelo tratamento no hospital-dia no período da coleta de dados, um psicoterapeuta da instituição e um coterapeuta também da instituição. Os pacientes constituíram um grupo heterogêneo quanto às características de gênero, idade, escolaridade, estado civil e diagnóstico psiquiátrico. A coleta de dados foi realizada no hospital-dia de um serviço universitário em uma cidade do interior paulista, sendo que a psicoterapia de grupo já fazia parte do programa deste serviço.

\section{Instrumentos}

As sessões de grupoterapias foram registradas via filmagem em VHS, sendo a filmadora instalada sobre um tripé e fixada somente no terapeuta. Simultaneamente, houve o registro manual das falas por um observador treinado para esse fim. Os prontuários dos pacientes foram consultados, com a devida autorização, para a caracterização destes.

\section{Procedimento}

A coleta de dados só teve início após o projeto ser aprovado pelo Comitê de Ética em Pesquisa da instituição e com 
o consentimento de cada paciente em participar. No início de cada sessão, por tratar-se de grupo aberto, retomava-se a explicação sobre o objetivo da pesquisa, explicando que durante algumas sessões os dados seriam coletados por um observador treinado, utilizando para isso uma filmadora, sendo que esta focalizaria apenas a imagem do terapeuta. Ressaltou-se o direito de cada um de participar ou não. Não houve recusas.

\section{Análise de dados}

Para a análise dos dados, o conteúdo das 15 sessões foi digitado na íntegra, deixando-se um espaço livre à direita da folha para o registro dos elementos temáticos. Para a organização dos dados, optou-se por seguir o modelo estrutural que as sessões já traziam, a saber, levantamento dos temas de interesse do grupo, composição da agenda, discussão dos temas e avaliação do grupo. Utilizou-se como regra de recorte, o assunto agendado e as afirmações explícitas sobre ele. Do grupamento das temáticas (assuntos) por convergências de conteúdos, originaram-se as categorias, que foram organizadas de acordo com os critérios apresentados por Bardin (1979), a respeito de uma "boa categoria", a saber: exclusão mútua, homogeneidade, pertinência, objetividade, fidelidade e produtividade.

\section{Resultados e Discussão}

\section{Características dos pacientes}

Os grupos eram heterogêneos quanto às características pessoais e ao diagnóstico psiquiátrico. Participaram dos grupos pacientes do gênero feminino (46\%) e masculino (54\%). A idade dos pacientes variou de 17 a 73 anos, sendo a faixa etária predominante entre 31 a 50 anos. A escolaridade ficou polarizada, pois havia pacientes com primeiro grau incompleto $(46 \%)$ e outros com escolaridade acima do $1^{\circ}$ colegial e curso superior (46\%). Quanto ao estado civil havia pacientes solteiros (46\%); casados (31\%); separados (15\%); amasiados $(4 \%)$ e viúvos $(4 \%)$. A maioria deles residia na cidade do HD $(70 \%)$ e o restante em cidades da região. Quanto à hipótese diagnóstica (dados coletados nos prontuários, efetuados segundo o CID-10): 50\% apresentavam o diagnóstico de Transtorno de Humor (com sintomas psicóticos); 38\% de Psicose sendo: 23\% Esquizofrenia; 7\% Transtorno Esquizoafetivo; 4\% Transtorno Delirante e 4\% Transtorno Psicótico Agudo e Transitório e 12\% de outros quadros sendo: 4\% Transtorno Somatoforme; 4\% Transtorno Obsessivo Compulsivo e 4\% Transtorno de Personalidade. Com relação à medicação: $65 \%$ dos pacientes utilizavam neurolépticos; 54\% ansiolíticos; 46\% antidepressivos; 7\% estabilizadores de humor e 3\% anticolinérgicos. Quanto à medicação combinada $54 \%$ dos pacientes utilizavam dois tipos; $35 \%$ somente uma e $11 \%$ tomavam três tipos de medicação.

\section{Funcionamento e composição dos grupos}

Os grupos eram abertos, sendo as admissões e altas dos pacientes vinculadas ao processo de alta e admissão no HD. As sessões eram diárias, com duração de uma hora. A média de participação nos grupos foi de onze pacientes, um terapeuta fixo e um co-terapeuta, ambos da instituição estudada. A condução dos grupos obedecia sempre à mesma sequência: nos primeiros minutos o terapeuta esclarecia o objetivo do grupo e quando havia novos membros retomava a sequência a ser seguida; os primeiros dez minutos eram para avisos e o agendamento dos assuntos a serem discutidos; após o agendamento apresentava a sequência dos temas indicados e coordenava a realização desta tarefa; nos dez minutos finais o terapeuta anunciava que a fase de discussão dos temas estava terminando e que o tempo restante seria dedicado a uma avaliação do encontro. Os grupos duravam exatamente 60 minutos.

\section{Temas discutidos e verbalizações nos grupos}

No transcorrer dos 15 grupos os pacientes agendaram 51 temas para discussão. Do grupamento desses temas, por semelhança de significado, organizaram-se seis categorias temáticas, apresentadas a seguir, com a respectiva frequência de verbalizações: sintomas $(28 \%)$, doença (18\%), tratamento e melhora (16\%), relacionamento interpessoal (16\%), hospital-dia (15\%) e alta (7\%). Os temas relacionados a sintomas geraram o maior número de falas, $28 \%$. Os sintomas estavam ligados à vivência pessoal de cada um motivando grande mobilização emocional e gerando maior número de verbalizações. Quanto à doença, as discussões mais frequentes foram sobre "qual o meu problema e minha expectativa de melhora" e "o preconceito da sociedade sobre a doença mental". Destacou-se, também, na discussão sobre tratamento e melhora "como se demonstra melhora ou piora" e "a resposta da família ao tratamento". Na categoria relacionamento interpessoal, os temas incidiram sobre a relação usuário-usuário; usuário-médico e usuário-família, destacando-se "como respondo frente aos pacientes que estão piores". Sobre o hospital-dia, predominou "como está a liberdade de cada um aqui no tratamento". A categoria temática menos discutida foi alta (7\%) sendo que "expectativa por ocasião da alta" foi o assunto mais discutido nesta categoria. Os pacientes que apresentaram menor verbalização nos grupos tinham em comum o episódio depressivo. Apesar da esquizofrenia ser um quadro onde os sintomas negativos poderiam dificultar a comunicação, este fator não influenciou a verbalização desses pacientes nos grupos (Louzã Neto, 1996). Também não se encontrou relação entre escolaridade e verbalizações.

No total dos grupos foram emitidas 2.459 verbalizações, sendo o terapeuta responsável por $44 \%$ das falas e os pacientes por $56 \%$. Para a discussão dos temas agendados ocorreram 634 falas, o que representou $26 \%$ das verbalizações totais. Os pacientes foram responsáveis por $70 \%$ dessas falas e o terapeuta por $30 \%$. Nas falas relacionadas aos fatores e manejos terapêuticos o terapeuta verbalizou $49 \%$ e os pacientes $51 \%$. 


\section{Técnicas mais usadas no manejo terapêutico grupal}

Predominou no processo grupal alguns fatores terapêuticos que Vinogradov e Yalom (1992) destacaram como necessárias ao manejo de grupos com pacientes psicóticos, a saber: apoio; ênfase no aqui-e-agora; e estrutura na condução dos grupos.

Apesar dos grupos serem heterogêneos os pacientes tinham em comum a doença mental, o sofrimento psíquico e o fato de estarem recebendo, neste período, tratamento no mesmo hospital-dia psiquiátrico. Bechelli e Santos (2004, p. 248) discutem que:

grupos com pacientes sofrendo da mesma condição facilitam a identificação, a revelação de particularidades e intimidades, o oferecimento de apoio ao semelhante, o desenvolvimento de objetivo comum, a resolução das dificuldades e dos desafios que se assemelham. Ao mesmo tempo, reduz o isolamento social e possível estigma, associado, dependendo da gravidade da doença e ao padecimento que a própria pessoa se impõe.

Os pacientes utilizaram o espaço grupal para discutir: a doença (18\% de verbalizações) e seus sintomas (28\%), representando a doença via sintomas e considerando-se curado quando os mesmos desapareciam. Esses elementos também se mostraram presentes no tema tratamento e melhora $(16 \%)$. Guanaes e Japur (2001a) encontraram em seu estudo com pacientes psiquiátricos ambulatoriais a doença como temática central e estes também relacionaram a doença com suas dificuldades e sintomas. Quanto ao tratamento recebido no HD, foram feitas colocações a seguir ilustradas: "Eu acho importante a enfermagem, os médicos, a física. Agora quem não gostar do tratamento não gosta de si próprio. Às vezes é difícil ficar aqui, mas eu sinto que está me ajudando" (Grupo 12).

Scherer e Scherer (2001), discutem a importância de cada serviço avaliar a satisfação de seus usuários, como uma maneira de nortear os serviços oferecidos. Os membros do grupo também discutiram sobre a alta $(7 \%)$. Pela pouca verbalização sobre a temática alta, acredita-se ser pertinente explorar em outros estudos a ressonância emocional gerada pelo desligamento do ambiente protegido e o retorno à sociedade. Esse conflito apareceu em algumas falas: "Eu queria sair hoje, porque eu estou bem, quero abrir minha oficina para trabalhar, mas quem sou eu?" (Grupo 11); "A gente pega uma confiança e afeição no médico e lá fora como a gente vai ser aceito?" (Grupo 4).

Scherer e Scherer (2001), em uma revisão sobre doentes mentais crônicos, discutem que a rejeição constitui-se em importante fator de desajuste social entre usuários de serviços de saúde mental e seus familiares, ou dos familiares entre si, o que contribui para uma difícil adaptação dos indivíduos à vida em comunidade, como ilustram as falas a seguir: "É difícil aceitar a perda de amigos e eu encontrei amigos aqui dentro" (Grupo 4); "É momento de parar e pensar bem: porque lá fora é diferente? (...) tem que pensar positivo e arrumar alguma coisa para fazer" (Grupo 4).

Bechelli e Santos (2005) ressaltaram que, no grupo, cada paciente é responsável pela maneira que interpreta e responde aos acontecimentos. Para obter benefícios e progredir, necessita estar aberto a interações com o grupo e às modificações necessárias em sua maneira de ver a si próprio, ao mundo e poder enfrentar de forma apropriada às circunstâncias da vida. Esse sentimento foi expresso na fala dessa paciente: "Ter planos é uma forma de deixar a chama da vida em pé. Eu acho que temos que sair daqui com planos" (Grupo 2).

$\mathrm{Na}$ discussão dos 51 temas propostos os pacientes utilizaram 56\% do total de falas, o que indica participação ativa na discussão de seus problemas e confirma os dados apontados por Bechelli e Santos (2002) sobre a importância do paciente no seu processo de mudança.

Os temas mais verbalizados estavam relacionados com a vivência dos pacientes (sintomas, relacionamentos interpessoais, preconceito e entendimento do problema). Os temas menos verbalizados... relacionavam-se a situações que geravam angústia tais como "alta", "perdas e limitações da doença", situações próximas à realidade, como o "esforço para vir ao HD", "como está minha participação no HD”. A avaliação do outro na relação interpessoal: "como se observam", "expectativa com a mudança dos médicos" e a "avaliação do coordenador do grupo".

Quanto ao manejo terapêutico, Contel (1997) discute que em grupos com pacientes psicóticos o terapeuta deve estar atento a apoiar e reorientar o paciente para a realidade sendo a melhor técnica o enfoque no aqui-e-agora do grupo. Deste modo os objetivos, segundo o autor, consistem em promover a expressão verbal; estimular a integração grupal de todos os usuários; formar um juízo sobre os ambientes interpessoais que frequenta; a aprendizagem interpessoal; assumir a responsabilidade por seu processo e a instilação de esperança. Algumas falas demonstraram esses aspectos:

Terapeuta: Isso é importante, então podemos começar discutindo o que cada um pode fazer pelo outro e qual o limite. Depois qual a direção que vou dar a minha vida quando sair do HD. (Grupo1)

Paciente: Foi importante a reunião, eu fico preocupado com quem não fala, eu quero passar alguma coisa boa para alguém por isso eu me expresso. Quem não fala... ninguém sabe o que o senhor tem, e o senhor não veio aqui para morrer, veio? (Grupo7)

Bechelli e Santos (2005) discutem que o cliente é o seu principal agente de mudança, ultrapassando o que deve existir em termos de técnicas ou abordagens, o que é percebido na fala do paciente descrita acima. Guanaes e Japur (2001a), ao estudarem pacientes psiquiátricos ambulatoriais, discutem que o entrosamento entre a necessidade do paciente e a capacidade do terapeuta em oferecer espaço são potencialmente 
terapêuticas. O funcionamento do grupo e a interação entre seus membros indicam sua utilização como espaço de queixa e desabafo, sendo que a participação dos outros pacientes se faz através de sugestões e conselhos, sobretudo frente às dificuldades nos relacionamentos sociais e afetivos. Neste estudo, também as falas foram dirigidas para a catarse e para o oferecimento de apoio através de sugestões e conselhos:

\section{Paciente: Estou preocupado que ele não fala. (Grupo7) \\ Terapeuta: Ele não consegue falar. Você está acom- panhando, que ele está preocupado com você? Você precisa começar a falar. (Grupo7) \\ Paciente: As pessoas começam a tirar sarro de mi- nha cara, acham que sou palhaço. (Grupo7) \\ Terapeuta: E aqui, acha que tem alguém tirando sarro na sua cara? (Grupo7) \\ Paciente: Eu acho que não. (Grupo7) \\ Terapeuta: Aqui é tratamento, nós não fazemos isso e o que estão te pedindo é que também comece a conversar. (Grupo7)}

Nas verbalizações diretamente ligadas à discussão dos assuntos agendados, a participação dos pacientes foi de $70 \%$ e a do terapeuta de $30 \%$, o que indica que o agendamento dos temas deu estrutura ao grupo, proporcionando a participação ativa dos usuários na sua condução. Mesmo nas verbalizações em que ocorreu o manejo terapêutico, a participação dos pacientes foi de $51 \%$ das falas, predominando o oferecimento de apoio e instilação de esperança.

Bechelli e Santos (2002) discutem em seu trabalho, que a força do grupo para a mudança provém de seus membros sendo o terapeuta apenas o regente da sessão, mantendo a estrutura do grupo e manejando os fatores terapêuticos, de modo a assegurar o andamento produtivo do mesmo. Neste trabalho constatou-se que os pacientes estão falando (56\% das falas totais), porém sob a coordenação de um terapeuta, que em função das características desses grupos, precisou ser ativo nas suas verbalizações (44\% das falas totais), confirmando a literatura que relata a necessidade de maior estrutura na condução de grupos com psicopatologias graves, com funcionamento de curto prazo, abertos e heterogêneos quanto às psicopatologias (Vinogradov \& Yalom, 1992; Zimerman \& Osório, 1997). Identificou-se que na condução desses grupos predominou o apoio, a ênfase no aqui-eagora e a estrutura constante em sua condução, conforme a apresentação abaixo.

\section{Apoio}

Conforme Vinogradov \& Yalom (1992) em razão do alto nível de ansiedade um agudo sentimento de crise vivenciado pelos pacientes, o terapeuta destes grupos deve oferecer apoio rápido e diretamente, conforme podemos observar nos trechos a seguir:
Terapeuta: Você não perdeu a capacidade de se explicar... (Gupo 6)

Paciente: Esta estória para mim está mal contada. (Grupo 6)

Terapeuta: Não, ele contou direitinho: o irmão se matou há dois anos atrás. Está certo e quando ele conta a gente chega mais perto dele. (Grupo 6)

\section{Ênfase no aqui-e-agora}

O foco no aqui-e-agora pode ajudar os pacientes a aprenderem habilidades interpessoais importantes: comunicação mais clara; aproximação com o outro; expressão de sentimentos positivos; atenção e capacidade para escutar; oferecimento de apoio; revelação de si mesmo, conforme exemplo abaixo:

Paciente: Sou sim (cheio de medo). Eu me deixo levar pelo sintoma e vou dando nome para o sintoma, estou com dor de cabeça e já penso em derrame. (Grupo 9)

Paciente: Pensamento positivo... (Grupo 9)

Terapeuta: $O$ que vocês acham que ele poderia fazer? (Grupo 9)

Paciente: É auto-sugestionamento, ele é hipocondríaco e pessimista em vez de transformar. (Grupo 9)

Terapeuta: Isso é o que nós achamos. Ao invés de colocar na cabeça que é derrame, o que ele poderia pôr? Uma outra coisa na cabeça? É possível a gente lidar com isso e colocar uma outra coisa na cabeça? (Grupo 9)

Paciente: Se eu fosse ele, eu, por exemplo, dou uma circulada. Você experimenta dar uma circulada, passear, ver os camelôs, dar uma volta no quarteirão. Comigo passa. (Grupo 9)

Terapeuta: É uma forma de se distrair... (Grupo 9)

Paciente: Ligar um rádio. (Grupo 9)

Terapeuta: Cada um vai encontrar o que é melhor, pode ser um rádio. (Grupo 9)

Paciente: Escrever! (Grupo 9)

Terapeuta: Pode ser escrever. (Grupo 9)

Paciente: (Fala desconexa) (Grupo 9)

Terapeuta: Você estava ótima até agora, eu vou te segurar quando você disparar.

Paciente: Tá! (Grupo 9)

Nesta transcrição o terapeuta e vários pacientes tentam ajudar um membro do grupo. Neste recorte há fatores terapêuticos, conforme Vinogradov e Yalom (1992): altruísmo, apoio, universalidade e instilação de esperança. Bechelli e Santos (2002) também discutem a importância dos fatores terapêuticos de universalidade, altruísmo, a instilação de esperança e o apoio mútuo, para ajudar cada membro do grupo ser agente de sua própria mudança. 


\section{Proporcionando estrutura}

A estrutura é oferecida de vários modos: instruindo e orientando os pacientes quanto à natureza e finalidade do encontro; estabelecendo limites de espaço e tempo muito claros para o grupo; usando um estilo pessoal claro, facilmente compreensível e confiante que ofereça reasseguramento aos pacientes ansiosos ou confusos e contribua para um sentimento de continência. O modo mais eficaz e explícito de se oferecer estrutura no setting é construindo-se em cada sessão uma seqüência consistente de eventos (Vinogradov \& Yalom, 1992).

Terapeuta: Esse grupo dura uma hora, vamos começar agora às $8 \mathrm{~h} 45 \mathrm{~min}$ e terminaremos às $9 \mathrm{~h} 45 \mathrm{~min}$. Primeiro, têm os avisos e depois escolhemos os assuntos. Podemos ter de dois a quatro assuntos e eu divido o tempo para que a gente possa conversar todos esses assuntos. No final da reunião, eu peço para vocês falarem o que vão levar. Então é importante prestar atenção. A finalidade dessa reunião é melhorar a escuta e além disso, coordenar os pensamentos para poder responder. Quem fala, ajuda e esse grupo é um grupo de conversa e se chama psicoterapia de grupo. Vocês têm esse grupo diariamente. Mais alguma coisa? Algum aviso? (Grupo 11)

Conforme salienta Contel (1997), adoecemos na relação com outras pessoas, portanto, nada melhor que a interação em grupo para percebemos em que ponto ou até que ponto vai a nossa responsabilidade pelas respostas do outro às nossas ações ou omissões. Aprende-se melhor, no grupo, a graduar a distância e a intimidade com as pessoas, em especial com psicóticos, que estão a confundir mundo interno e mundo externo.

Paciente: Eu acho que eu tenho uma grande liberdade aqui dentro, apesar de terem me segurado ontem de ir ao banheiro. Eu entendo o porquê me seguraram no grupo. Para eu conhecer as pessoas, para aprender a lidar comigo mesma. (Grupo 12) Terapeuta: Esse grupo é de uma hora, e se a pessoa entra e sai, atrapalha o funcionamento do grupo $e$ como é um lugar para pensar, tem que ficar para a cabeça funcionar. (Grupo 12)

Paciente: Eu posso ser franca? Eu tenho vontade de ir ao banheiro agora, mas não vou. (Grupo 12)

Terapeuta: A sugestão é fazer xixi antes. (Grupo 12)

A coordenação de grupos com pacientes psicóticos requer do coordenador um manejo diretivo, conforme apontam Vinogradov e Yalon (1992, p.148-149):

Os terapeutas devem considerar a vida de um grupo para pacientes internados como sendo de apenas uma sessão e devem lutar para oferecerem algo útil para tantos pacientes quanto possível, durante esta sessão. Uma estrutura de tempo de sessão única demanda eficiência. Não se pode desperdiçar tempo: o líder tem apenas uma única oportunidade para engajar cada paciente e não deve perdê-la. Esta necessidade por eficiência demanda maior atividade do terapeuta. Este deve estar preparado para ativar o grupo, chamar os membros, apoiá-los e interagir pessoalmente com eles.

Identificou-se através da análise quantitativa e também da qualitativa que a estrutura na condução dos grupos foi oferecida pela participação ativa do terapeuta, que utilizou $30 \%$ das falas para a discussão dos temas e $49 \%$ para o manejo terapêutico do grupo, contudo isso não impediu de modo algum a participação dos pacientes. Apesar desses grupos não serem constituídos apenas por pacientes psicóticos, esse diagnóstico predominou, pois havia 50\% de usuários com transtorno de humor (com sintomas psicóticos) e 38\% de usuários com psicoses, além de tratar-se de um grupo aberto onde cada sessão foi considerada única, devendo o terapeuta ser ativo e apoiador, nas palavras de um paciente: "É difícil. A gente cria confusão, às vezes parece fácil e torna difícil, e outra hora o difícil parece fácil” (Grupo 2).

\section{Considerações finais}

As grupoterapias funcionaram como estímulo à atitude menos passiva e mais crítica dos pacientes frente à doença, à instituição onde são tratados e à sociedade de uma maneira geral. Proporcionaram também espaço para suas falas, as quais, por sua vez, foram significadas e legitimadas pelo grupo. Sugere-se a análise de conteúdo de outros grupos, em períodos diversos e em outros hospitais-dia psiquiátricos para um estudo comparativo com os dados encontrados nesta casuística.

\section{Referências}

Bardin, L. (1979). Análise de Conteúdo. Lisboa: Edições 70.

Bechelli L. P. C., \& Santos M. A. (2001). Psicoterapia de grupo: Noções básicas. Ribeirão Preto, SP: Legis Summa.

Bechelli L. P. C., \& Santos M. A. (2002). Psicoterapia de grupo e considerações sobre o paciente como agente da própria mudança. Revista Latino-Americana de Enfermagem, 10, 383-391.

Bechelli L. P. C., \& Santos M. A. (2004). Psicoterapia de grupo: Como surgiu e evoluiu. Revista Latino-Americana de Enfermagem, 12, 242-249.

Bechelli L. P. C., \& Santos M. A. (2005). O paciente na psicoterapia de grupo. Revista Latino-Americana de Enfermagem, 13, 118-125. 
Bezerra Junior, B. (1992). Considerações sobre terapêuticas ambulatoriais em saúde mental. In S. A. Tunis \& N. R. Costa (Orgs.), Cidadania e loucura: Políticas de saúde mental no Brasil (3a ed., pp. 133-169). Petrópolis, RJ: Vozes.

Contel, J. O. B. (1991). Quinze anos de hospital-dia: Contribuição ao estudo da prática de comunidade terapêutica, psicoterapia de grupo e princípios psicanalíticos em hospital psiquiátrico no Brasil. Jornal Brasileiro de Psiquiatria, 40, 163-169.

Contel, J. O. B. (1997). Prática com grupos especiais: Psicoterapia de grupo com pacientes internados e egressos. In D. E. Zimerman \& L. C. Osório (Orgs.), Como trabalhamos com grupos (pp. 268-82). Porto Alegre: Artes Médicas.

Contel, J. O. B., Agostini, M., Peduzzi, M., Santos, S. A., Castaldelli, A. A., \& Oliveira, A. S. (1993). Grupoterapia em hospital-dia: Os grupos das comissões de atividade. Jornal Brasileiro de Psiquiatria, 42, 327- 34.

De Tílio, R. (2007). A querela dos direitos: Loucos, doentes mentais e portadores de transtornos e sofrimentos mentais. Paidéia (Ribeirão Preto), 17, 195-206.

Guanaes, C., \& Japur, M. (2001a). Fatores terapêuticos em um grupo de apoio para pacientes psiquiátricos ambulatoriais. Revista Brasileira de Psiquiatria, 23, 13440.

Guanaes, C., \& Japur, M. (2001b). Grupo de apoio com pacientes psiquiátricos ambulatoriais em contexto institucional: Análise do manejo terapêutico. Psicologia: Reflexão e Crítica, 14, 191-199.

Guimarães, A. C. P. C. (1998). Grupoterapia em hospital-dia psiquiátrico: Uma revisão da literatura [Resumo]. Anais do ciclo de saúde mental, 4. Ribeirão Preto, SP: FMRP/ USP.

Guimarães, A. C. P. C. (2001). Grupoterapia em hospitaldia: Uma análise temática de quinze sessões. Dissertação de mestrado não-publicada, Universidade de São Paulo, Ribeirão Preto, SP.

Guimarães, A. C.P.C., \& Contel, J. O. B.(2006). Time-limeted multimodal group practice for mixed psychotic disorders in a university psychiatric day hospital [Abstract]. Groups: Connecting Individuals, Communities and cultures, 1, 76-77. Trabalho apresentado no International Congress of Group Psychotherapy, 16, São Paulo.

Louzã Neto, M. R. (1996). Convivendo com a esquizofrenia. São Paulo: Lemos.

Scherer, Z. A. P., \& Scherer, E. A. (2001). O doente mental crônico internado: Uma revisão da literatura. Revista Latino-Americana de Enfermagem, 9, 56-61.

Tapia, J. E. R., Contel J. O. B., \& Campos, M. A. (1997). Visão de mundo em hospital-dia psiquiátrico: Exegese existencial de textos científicos de equipe terapêutica. Jornal Brasileiro de Psiquiatria, 46, 223-226.
Vinogradov, S., \& Yalom, I. D. (1992). Manual de Psicoterapia de grupo (D. Batista, Trad.). Porto Alegre: Artes Médicas.

Zimerman, D. E., \& Osório L. C. (Orgs.). (1997). Como trabalhamos com grupos. Porto Alegre: Artes Médicas.

Ana Celina Pires de Campos Guimarães é Professora do Departamento de Psicologia da Universidade do Sagrado Coração, Bauru-SP.

José Onildo Betioli Contel é Professor Associado do Departamento de Neurologia, Psiquiatria e Psicologia Médica da Faculdade de Medicina de Ribeirão Preto da Universidade de São Paulo.
Recebido: $30 / 04 / 2008$

$1^{a}$ revisão: $30 / 01 / 2009$

$2^{a}$ revisão: 01/04/2009

$3^{a}$ revisão: $26 / 04 / 2009$

Aceite final: $28 / 07 / 2009$ 